\title{
Efficacy of pain control following Lower Segment Cesarean Delivery under Intrathecal Anaesthesia And the need for opioid use in the first 24 hours
}

Authors: Lal S', Narayanan N2, Thomas J2, Malik A², Singh V2, Gwyneth M Mahoko3 Department of Anesthesiology and Critical Care Our Lady of Lourdes Hospital, Drogheda, Ireland

I registrar 2 consultant 3 Pain nurse

\section{Background}

Inadequate Pain relief following Lower segment C-Section slows recovery, reduces patient's level of satisfaction and increases hospital stay. ${ }^{1,2,3}$ Use of intra-thecal morphine is now widely accepted for analgesia during and following caesarean section because it promotes adequate and longlasting postoperative analgesia even at low doses. ${ }^{4,5}$ However, it may cause side effects such as nausea, vomiting, pruritus, sedation, and respiratory depression. The quality of analgesia and incidence of side effects may vary according to the intra-thecal dose of morphine used ${ }^{5}$. 100 micrograms is considered safe ${ }^{6}$. Inadequately controlled pain in the postoperative period can lead to the development of chronic pain.

\section{Aims:}

Aim of this audit is to assess the efficacy of pain relief following surgery with reference to consumption of opioids in first 24 hours and possible solutions to treat inadequate pain relief post operatively in nursing mothers.

\section{Methodology:}

After taking approval from the local audit committee, data of 50 patients (elective/emergency) was collected. Consumption of Opioids, Paracetamol, NSAIDS and side effects were recorded in the first 24 hours following surgery.

PERCENTAGE OF PATIENTS WHO CONSUMED OPIOIDS IN THE FIRST 24 HOURS FOLLOWING SURGERY.

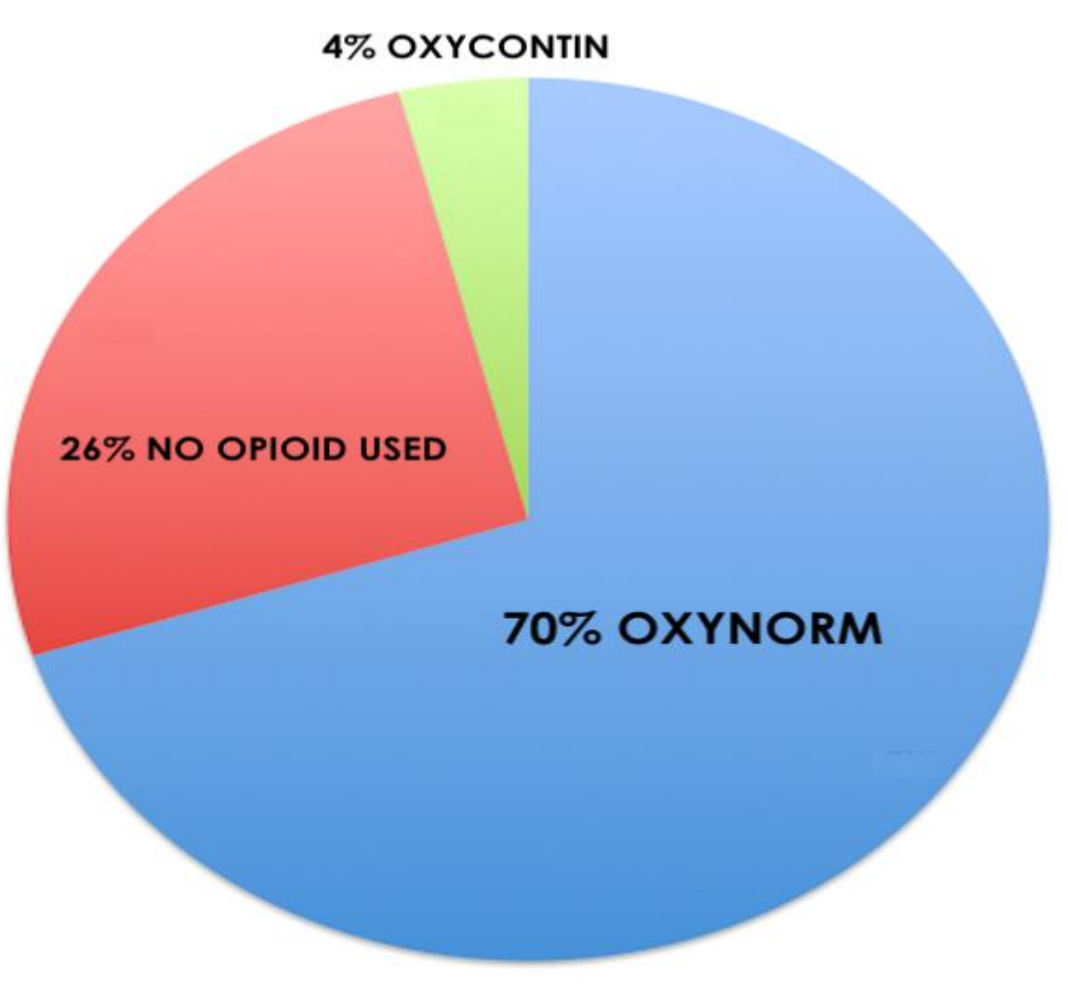

Result : 74\% of patients consumed Opioids in the first 24 hours following Caesarean Section under Intrathecal Anaesthesia. All patients received Paracetamol 1 gram PR and Diclofenic $100 \mathrm{mg}$ PR in the immediate post operative period in the theatre.

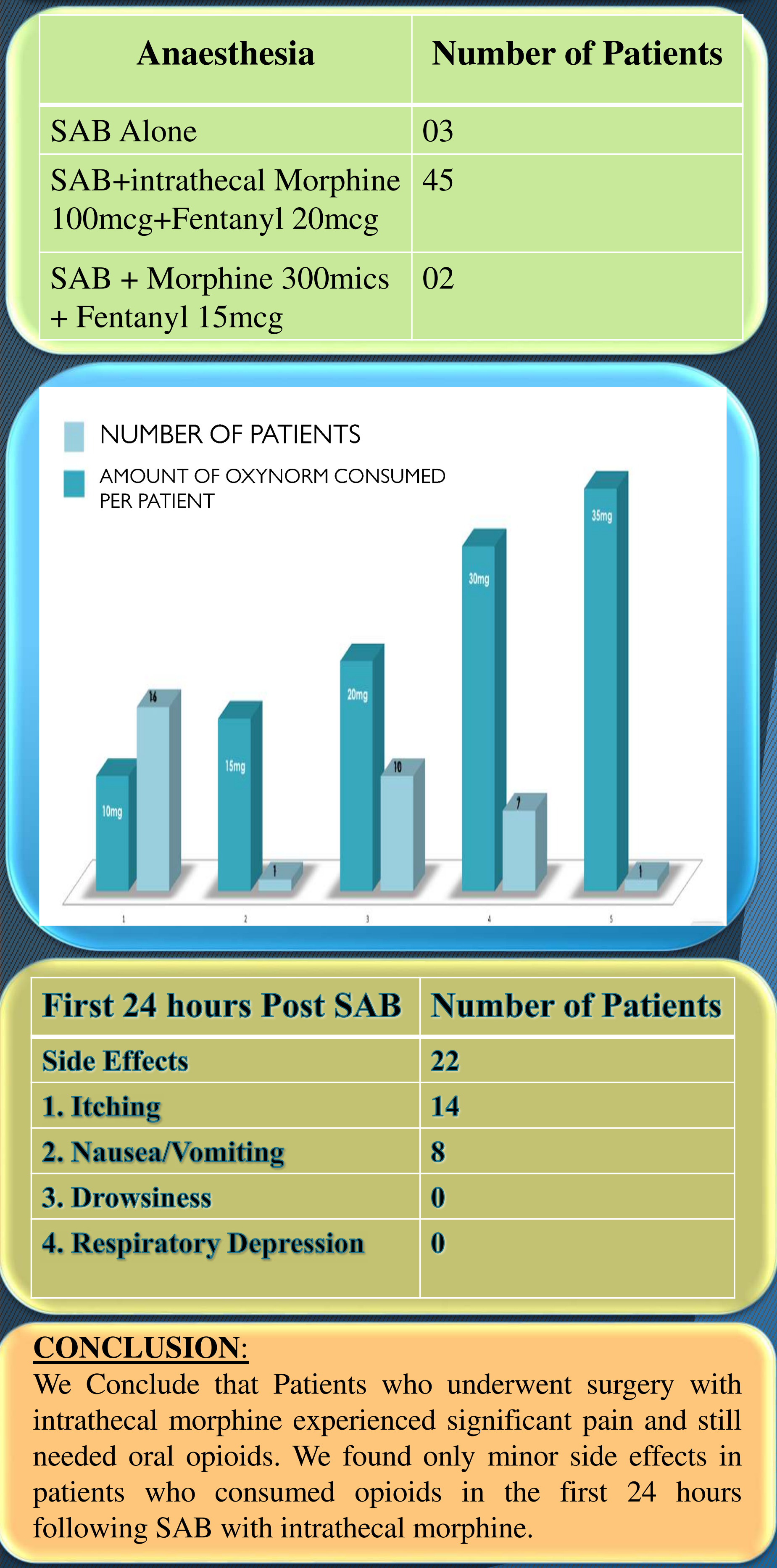

